\title{
Portuguese academic staff and students in UK's engineering higher education
}

\author{
Inês Direito \\ Centre for Engineering Education \\ University College London (UCL) \\ London, United Kingdom \\ i.direito@ucl.ac.uk
}

\author{
Stella Fowler \\ Engineering Professors' Council \\ United Kingdom \\ s.fowler@epc.ac.uk
}

\begin{abstract}
Before the EU referendum in June 2016, the proportion of European nationals in engineering and technology in UK's higher education was $19 \%$ for academic staff, $6 \%$ and $15 \%$ for students (undergraduate and postgraduate, respectively). This paper presents an overview of the number of Portuguese academic staff and students working and studying in the UK, from 2007/08 to 2015/16. For students, a breakdown by level of study, university type (member or not member of Russell Group), engineering discipline and gender are provided, as well as data of the first cohort of students starting their Engineering programs following the 2016 Brexit referendum.
\end{abstract}

Keywords-engineering students; engineering academic staff; level of study; gender; engineering discipline

\section{INTRODUCTION}

In the United Kingdom, the Higher Education Statistics Agency (HESA) holds large datasets on all aspects of the higher education sector. This includes information about: students, qualifiers and graduates; academic and non-academic staff; universities and other education providers. These datasets can be assessed by subscribers (higher education providers and notfor-profits) on Heidi Plus - a software that provides access and enables tailored data analysis to answer to specific research questions.

According to public reports based on the analysis HESA Staff Data [1], the proportion of European (EU) academic staff in Engineering and Technology was 10\% in 2006/07 and 19\% in $2015 / 16$. As for students, the majority of those entering a first degree in engineering and technology (undergraduate) in 2015/16, 71\% were of UK origin, $6 \%$ from EU countries, and $23 \%$ from other nationalities [2]. The opposite was found at postgraduate level, with only $25 \% \mathrm{UK}, 15 \%$ EU and $60 \%$ other nations. However, these public reports do not provide detailed figures for different nationalities, for both students and staff.

In order to explore data trends of Portuguese academic staff and students (at undergraduate and postgraduate level) in the UK's engineering higher education sector, this paper provides brand new data analysis on the most recent datasets. It aims to respond to the following research questions:
- How has the number of Portuguese academic staff working in UK Engineering Higher Education institutions changed in the last years;

- How has the number of Portuguese students in UK Engineering Higher Education institutions changed in the last years;

- What is the distribution of Portuguese engineering students by level of study, gender, type of university and engineering discipline;

- What is the impact of the UK's decision to leave the UK on the number of Portuguese engineering students.

\section{A. HESA data}

The figures provided for both academic staff and students are full person equivalent (FPE). FPE looks at how much of one person's studying or working time is engaged in a particular activity. Students' breakdown by subject data is provided with a count of FPE. Staff can hold more than one contract with a university, so FPE is preferable to full-time equivalent (FTE).

Due to data protection policies, HESA implemented a rounded and suppression strategy in published and released tabulations designed to prevent the disclosure of personal information about any individual. Counts of people are rounded to the nearest multiple of 5, and any number lower than 2.5 is rounded to 0 . This is valid for staff as well as for students.

Compound annual growth rates (CAGR) were calculated to compare academic staff and student numbers over nine academic years, using the formula below,

Where,

$$
\operatorname{CAGR}\left(t_{0}, t_{1}\right)=\left(\frac{V\left(t_{n}\right)}{V\left(t_{0}\right)}\right)^{\frac{1}{t_{n}-t_{0}}}-1
$$

$\mathrm{t}_{0}$ - the first year of observations (2007/08)

$\mathrm{t}_{1}$ - the last year of observations $(2015 / 16)$

$\mathrm{V}\left(\mathrm{t}_{0}\right)$ - the start value

$\mathrm{V}\left(\mathrm{t}_{1}\right)$ - the last value observed 


\section{B. Academic staff}

Data for Portuguese academic staff was analysed by academic employment (academic staff only, including teaching, research, teaching and research, or neither teaching nor research), gender (male, female), discipline (cost centre 'engineering and technology', comprising: General engineering; Chemical engineering; Minerals, metallurgy \& materials engineering; Civil engineering; Electrical, electronic \& computer engineering; Mechanical, aero \& production engineering; IT, systems sciences \& computer software engineering) and age (34 years and under; 35-49 years; 50-65 years) [3].

The 2016/17 academic staff data is expected to be published in March 2018.

\section{Students}

Data for Portuguese students was extracted domicile, which represents the country of permanent home address prior to entry to the course - used as a proxy for nationality. The data were further analysed by gender, level of study, discipline and mission group.

Level of study provides the breakdown figures by: first degree (undergraduate), postgraduate research, and postgraduate taught.

Postgraduate research (PGR) includes doctorate, masters degree and postgraduate diplomas or certificates studied primarily through research. PGR students will be trained in research methods and are expected to do a research project. It is usually a pre-requisite for a $\mathrm{PhD}$. Full-time programmes usually last 18 months. Because there are fewer teaching costs, fees for master's by research are usually lower than for a taught master's.

On the other hand, postgraduate taught students (PGT) are those studying for a qualification mostly by a taught method (learning by teaching), although there may be a research element. Full-time courses are normally one year long [4].

Engineering disciplines are coded by HESA by principal subject which does not exactly matches the engineering disciplines provided for staff data. These are: general engineering; civil engineering; mechanical engineering; aerospace engineering; naval architecture; electronic \& electrical engineering; production \& manufacturing engineering; chemical process \& energy engineering; and others in engineering.

In the UK, higher education institutions are commonly grouped in 'mission groups'. The Russell Group is a selfselected group of research-led universities. Data was analysed by university type (Russell Group's member vs. non-member).

\section{DATA TRENDS}

\section{A. Academic staff}

The number of FPE academic staff with Portuguese nationality working in UK's higher education institutions was around 50 between 2007/08 and 2010/11. For the reported period of data, the number of Portuguese staff almost tripled, with an increase of $150 \%$ for male, and $175 \%$ for female (Figure $1)$.

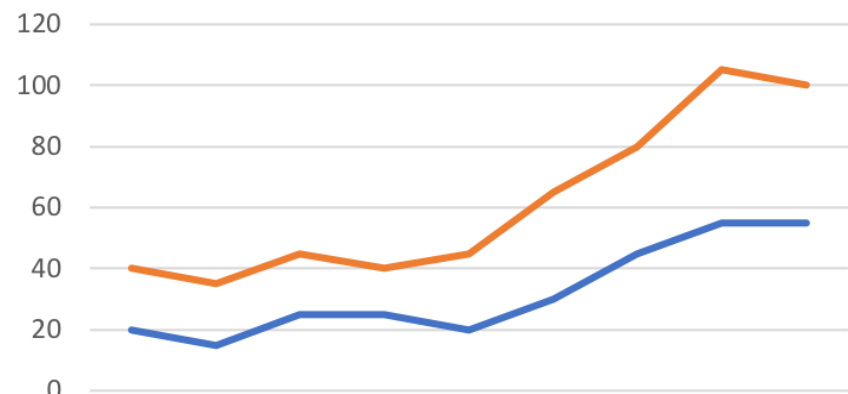

07/08 08/09 09/10 10/11 11/12 12/13 13/14 14/15 15/16

$$
\text { Female Male }
$$

Figure 1. Number of academic staff by gender

\section{B. Students}

- Level of study

Over the last nine years, up until the 2016 referendum, the number of undergraduate students (UG) registered in engineering higher education courses in the UK declined (CAGR $=-2.0 \%$ ), reaching a lower value in 2011/12. However, the number of Portuguese students registered in UK engineering courses after the Brexit referendum increased $23.5 \%$ since $2015 / 16$, shooting up to the highest level in ten years of available data.

Recent data from UCAS [5], providing a first glimpse into 2018/19 enrolments, shows there has been a rise in international applications, including a 3\% rise from European students, across the HE sector, which some commentators have read as a rush to study in the UK before Brexit. However, these data also shows no rise for Engineering applications from within the EU (-1.7\%) for the upcoming academic year.

As for postgraduate degrees, in the nine years prereferendum, there was also a decrease in PGT $(\mathrm{CAGR}=-3.1 \%)$, and a slight increase in PGR $(\mathrm{CAGR}=1.6 \%$ ) (Figure 2$)$. Contrary to UG figures, both PGT and PGR numbers in 2016/17 decreased, compared to the previous year, by $14.3 \%$ and $11.8 \%$ respectively. This may suggest that postgraduate degrees have become less attractive to Portuguese students after the referendum results.

- Level of study and gender

Between 2007/08 and 2015/16, when levels of study were analysed by gender (Figure 3), the number of female students in undergraduate programmes remained the same $(\mathrm{CAGR}=0 \%)$ and the male numbers decreased $(\mathrm{CAGR}=-2.3 \%)$. There was also a decrease on male students numbers on both PGT (CAGR $=-4.1 \%)$ and PGR $(\mathrm{CAGR}=-1.2 \%)$. The number of female students in PGT studies remained constant in the last 9 years, contrasting with PGR, with a compound annual growth rate of $7.2 \%$

After the referendum, the growth in UG numbers was equally observed for both male and female students $(24.1 \%$ and $20 \%$, respectively). The same pattern was found for PGR (- 10\% 
for male students, and $-14.3 \%$ for female students). Curiously, in PGT the decrease on student numbers was registered for female students only, with an increase of $20 \%$ for male students, compared to $2015 / 16$.
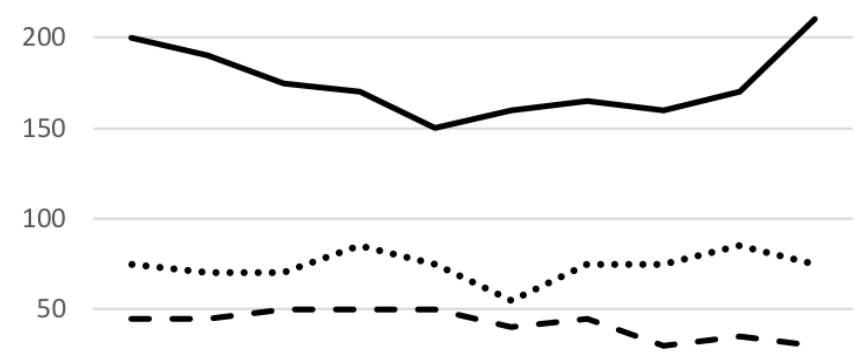

0

07/08 08/09 09/10 10/11 11/12 12/13 13/14 14/15 15/16 16/17

$$
\text { ....PPGR - -PGT } \longrightarrow U G
$$

Figure 2. Number of students by level of study

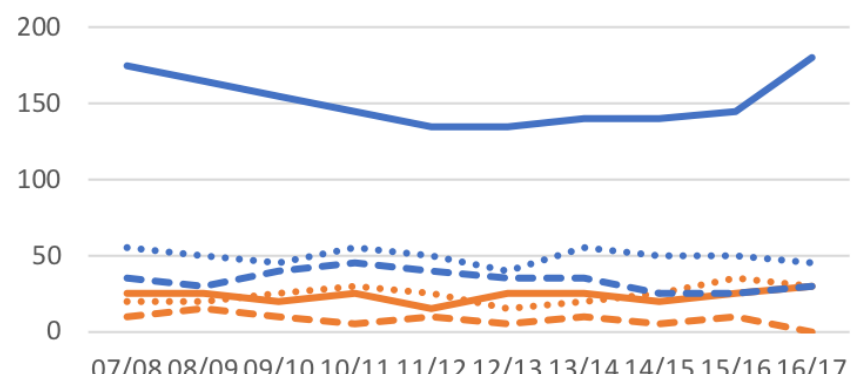

07/08 08/09 09/10 10/11 11/12 12/13 13/14 14/15 15/16 16/17

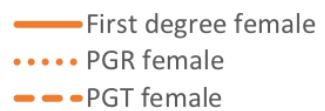

First degree male

.....PGR male

- - PGT female

- -PGT male

Figure 3. Number of students by level of study and gender

- Level of study and type of university

When analysed by type of university, most of undergraduate students were registered in a non-Russell Group University (Figure 4). The figures for this degree level in institutions that are not members of the Russell Group have been decreasing across the last nine years before the referendum $($ CAGR = $5.1 \%$ ). On the contrary, the number of undergraduate students registered in Russell-Group institutions have been increasing $(\mathrm{CAGR}=6.3 \%)$.

The available data suggests that, after the referendum, the growth of students in non-member institutions was higher $(\mathrm{CAGR}=33.3 \%)$ than the growth in Russell-Group institutions $(\mathrm{CAGR}=7.7 \%)$, in comparison to $2015 / 16$.

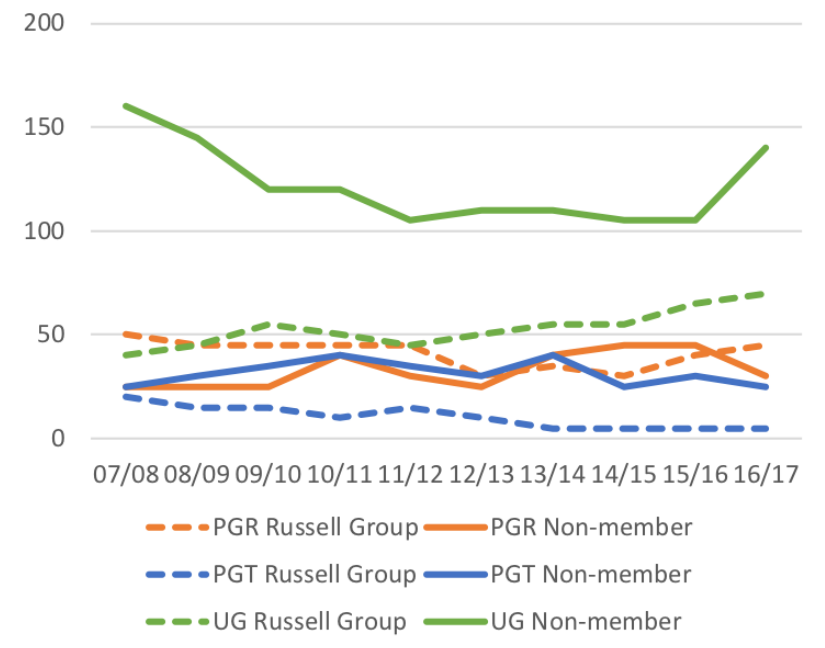

Figure 4. Number of students by level of study and type of university

Regarding postgraduate level, the number of Portuguese students in PGT programmes offered by Russell-Group institutions decreased by $15.9 \%$, and slightly decreased for PGR $(\mathrm{CAGR}=-2.8 \%)$. The number of students in programmes delivered by non-member institutions increased by $7.6 \%$ for PGR, and $2.3 \%$ for PGT.

At postgraduate level, the referendum seems to have had a negative impact in the growth rate of Portuguese students studying in non-member institutions, in comparison to 2015/16, with a decrease of $33.3 \%$ for PGR and $16.7 \%$ for PGT. For Russell-Group institutions, the number of Portuguese students in PGR programmes increased by $12.5 \%$.

- Undergraduate level and engineering discipline

The breakdown figures by postgraduate study and discipline were too small to provide a meaningful pattern for analysis, and are not presented in this paper.

When analysing the number of undergraduate students by discipline (Figure 5), mechanical engineering, although decreasing in the last nine years $(\mathrm{CAGR}=-4.5 \%)$, was the most popular amongst Portuguese students. It was followed by electronic and electrical engineering $(\mathrm{CAGR}=-7.1 \%)$, and civil engineering $(\mathrm{CAGR}=-3.5 \%)$. Although less popular amongst Portuguese students, aerospace engineering and chemical engineering have been growing $(\mathrm{CAGR}=3.7 \%$ and $\mathrm{CAGR}=$ $5.2 \%$, respectively).

Compared to the 2015/16 academic year, electronic and electrical engineering had a growth of $80 \%$ in $2016 / 17$, followed by mechanical engineering, with a growth of $55 \%$. 
80

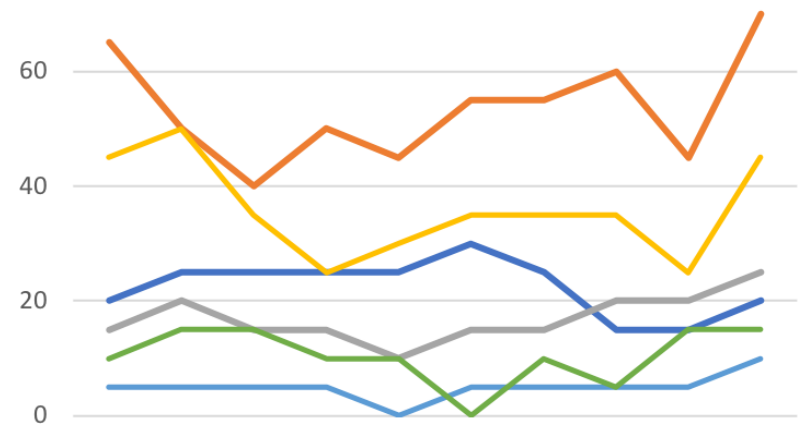

07/08 08/09 09/10 10/11 11/12 12/13 13/14 14/15 15/16 16/17

$$
\begin{aligned}
& \text { Civil Mechanical Aerospace } \\
& \text {-Electrical _Product Chemical }
\end{aligned}
$$

Fgure 5. Number of undergraduate students by engineering discipline.

\section{SUMMARY}

This paper gives a brief overview of the number of Portuguese academic staff and students working and studying in UK engineering higher education. Its aims were threefold: understand the workforce mobility of Portuguese academics into the UK; understand Portuguese students' preferences for engineering discipline and type of university; and analysis of the impact of Brexit on student numbers at both undergraduate and postgraduate levels.

The impact of Brexit on staff numbers working in engineering higher education institutions in the UK is still to be analysed once relevant data is published by national agencies, but anecdotes suggest an increase in departures of
European staff from universities amid concerns over post-Brexit rights and funding.

Data on student numbers suggest that Portuguese students prefer to study in the UK at undergraduate level, and at institutions that are not part of the Russell Group, with a higher number represented in mechanical engineering and electrical and electronic engineering. The number of students that started a first degree in engineering in 2016/17 suggests that Brexit have not had a negative impact. However, data from the current academic year, not yet published, will help to provide a clear picture.

\section{REFERENCES}

[1] Universities UK (UUK), 2017. Patterns and trends in UK higher education. http://www.universitiesuk.ac.uk/facts-and-stats/data-andanalysis/Documents/patterns-and-trends-2017.pdf

[2] Engineering UK, 2017. The 2017 Engineering UK: the state of engineering report. https://www.engineeringuk.com/media/1356/enguk_report_2017_synop sis.pdf

[3] Higher Education Statistics Agency (HESA): Staff record [online] Available: https://www.hesa.ac.uk/collection/c17025/coverage (Accessed: 29 January 2018)

[4] Universities and Colleges Admissions Service (UCAS) [online] Available: https://www.ucas.com/ucas/postgraduate/postgraduatestudy/what-study

(Accessed: 29 January 2018)

[5] UCAS UK application rates by the January deadline - 2018 Cycle https://www.ucas.com/file/147891/download?token=sjxwG1wA 